\title{
AVALIAÇ̃̃O EM LARGA ESCALA EM MUNICÍPIOS BRASILEIROS: O QUE DIZEM OS NÚMEROS?
}

ADRIANA BAUER

CLAUDIA OLIVEIRA PIMENTA JOÃO LUIZ HORTA NETO SANDRA ZÁKIA LIAN SOUSA

* Este texto é uma versão ampliada e com dados atualizados do trabalho apresentado no III Congresso Naciona de Avaliação em Educação, realizado em Bauru, em 2014

\section{RESUMO}

0 artigo, que se organiza em quatro seções, apresenta resultados de pesquisa que teve por objetivos mapear e caracterizar iniciativas relacionadas às avaliações em larga escala em desenvolvimento nos municípios brasileiros. Inicialmente, expõe-se uma síntese de estudos já produzidos sobre a temática e, em seguida, são explicitados os procedimentos metodológicos do estudo. $\mathrm{Na}$ terceira seção, discutem-se resultados obtidos na fase preliminar do survey, que abarcam manifestações obtidas de 4.309 municípios. Por fim, são apontadas conclusões acerca de concepções presentes nas avaliações propostas pelos municípios e dos usos dos resultados que as gestões desses entes federados fazem das diversas avaliações existentes, que evidenciam a consolidação da avaliação em larga escala como instrumento de gestão educacional nas municipalidades.

PALAVRAS-CHAVE AVALIAÇÃO EDUCACIONAL • GESTÃO EDUCACIONAL • SURVEY • POLÍTICA DE AVALIAÇÃO DOS MUNICÍPIOS. 


\section{RESUMEN}

El artículo, que se organiza en cuatro secciones, presenta resultados de una investigación que tuvo el objetivo de mapear y caracterizar iniciativas relacionadas con las evaluaciones en gran escala que se llevan a cabo en los municipios brasileños. Inicialmente, expone una síntesis de estudios ya realizados sobre la temática y luego explicita los procedimientos metodológicos del presente estudio. En la tercera sección, discute resultados que se obtuvieron en la fase preliminar del survey, que abarcan manifestaciones recogidas en 4.309 municipios. Por fin, presenta conclusiones acerca de concepciones presentes en las evaluaciones propuestas por los municipios y de los usos de los resultados que las gestiones de dichos entes federados hacen de las diversas evaluaciones existentes, que ponen de manifiesto la consolidación de la evaluación en gran escala como instrumento de gestión educacional en las municipalidades.

PALABRAS-CLAVE EVALUACIÓN EDUCACIONAL • GESTIÓN EDUCACIONAL • SURVEY • POLÍTICA DE EVALUACIÓN DE LOS MUNICIPIOS.

\section{ABSTRACT}

The article, organized in four sections, presents results of a study that aimed to map and characterize initiatives related to large-scale assessments in development in Brazilian municipalities. Initially, it presents a synthesis of studies already available on the subject, and then explains the methodological procedures of the study. In the third section, it discusses results obtained in the preliminary phase of the survey, which covers events from 4,309 municipalities. Finally, it draws conclusions about the concepts present in the reviews proposed by municipalities and how the results of the various existing evaluations are used by the administration of these federated entities, which highlight the consolidation of large-scale evaluation as a tool for educational management in the municipalities.

KEYWORDS EDUCATIONAL EVALUATION • EDUCATIONAL MANAGEMENT • SURVEY • EVALUATION POLICY OF THE MUNICIPALITIES. 
1 Pesquisa intitulada "Avaliação e gestão educacional em municípios brasileiros: mapeamento e caracterização de iniciativas em curso", desenvolvida por meio de parceria entre a Fundação Carlos Chagas (FCC) e o Instituto Nacional de Estudos e Pesquisas Educacionais Anísio Teixeira (Inep). O referido estudo busca identificar as iniciativas de avaliação educacional que vêm sendo desenvolvidas nos municípios

em três dimensões - avaliação de

alunos, avaliação institucional e

avaliação de profissionais -, bem como compreender a apropriação, pelos municípios, das avaliações em larga escala já existentes.

\section{INTRODUÇÃO}

Este artigo apresenta resultados parciais de uma pesquisa mais ampla, ${ }^{1}$ que tem como propósito caracterizar o lugar que a avaliação externa e em larga escala, promovida por diferentes entes da federação, vem ocupando na gestão da educação municipal e suas eventuais implicações em ações desenvolvidas pelos municípios.

Estudos já divulgados (BAUER, 2012; BAUER; REIS, 2013; HORTA NETO, 2013; SOUSA, 2013; BONAMINO, 2013; BROOKE; CUNHA; FALEIROS, 2011) têm mencionado a crescente expansão de iniciativas de avaliação em larga escala, implementadas pelo governo federal ou por governos estaduais, especialmente após a criação, em 2007, do Índice de Desenvolvimento da Educação Básica (Ideb) pelo Inep. Em levantamento realizado em 2011, Brooke, Cunha e Faleiros apontavam a existência de iniciativas de avaliação em larga escala em 19 estados brasileiros, evidenciando que tais iniciativas inauguram uma nova forma de gestão educacional, apoiada nos dados obtidos. Os autores discutem, ainda, os tipos de uso dos resultados dessas avaliações externas para 
a gestão, destacando que, naquele momento, os resultados eram utilizados para avaliar e orientar a política educacional, informar as escolas sobre a aprendizagem dos alunos e ao público sobre os resultados obtidos e subsidiar a formação continuada e as decisões sobre alocação de recursos. Foi ressaltado, ainda, o uso dos resultados para propor políticas de incentivos salariais e de certificação de alunos e de escolas.

Ao lado desse movimento de apropriação de resultados de avaliações que se realizam sob responsabilidade dos estados, há registros que indicam a disposição dos municípios em adotar sistemas avaliativos próprios, sejam esses concebidos pelas secretarias de educação, ou por empresas contratadas pela administração municipal.

Com recortes e objetivos específicos, já se dispõe de pesquisas que permitem uma aproximação com experiências municipais, embora se caracterizem como estudos que abrangem um ou alguns casos e iluminam uma compreensão inicial de trilhas que vêm pautando o significado da avaliação na gestão educacional de municípios e escolas do país. $^{2}$ Nos limites deste artigo, são referenciados alguns desses estudos, que possibilitam ilustrar suas contribuições.

Bauer (2014), ao fazer levantamento bibliográfico de teses e dissertações sobre a temática das avaliações de sistemas educacionais e sua relação com a gestão educacional, aponta a existência de diversos estudos que revelam como as práticas de avaliação e gestão têm se imbricado em municípios brasileiros. Os estudos de Figueiredo (2008) e Lima (2011) tratam, respectivamente, do papel do Sistema de Avaliação do Rendimento Escolar Municipal (Sarem) da Secretaria Municipal de Educação de Cosmorama, na melhoria das aprendizagens dos alunos, e do papel do Sistema de Avaliação do Desempenho das Instituições Educacionais do Sistema de Ensino do Distrito Federal (Siade), no subsídio ao trabalho de diretores escolares desse município.

Pesquisa realizada por Ferrarotto (2011) buscou acompanhar a implementação do Programa Municipal de Avaliação do Sistema de Ensino (Promase), implantado em 2006 no município de Amparo-SP, para apreender seus eventuais efeitos em práticas adotadas pela Secretaria Municipal de Educação
2 Em levantamento bibliográfico realizado na esfera da pesquisa em pauta, foram identificados 134 estudos, entre teses, dissertações e artigos, que têm como escopo investigar eventuais efeitos de avaliações externas em propostas e práticas de redes ou escolas de diversos municípios brasileiros. 
e por escolas da rede. Foram realizadas entrevistas com a Secretária de Educação, as gestoras de escolas e os professores, análise documental e observação de quatro escolas municipais. Entre as revelações apontadas pela autora, registram-se, com base nos resultados da avaliação externa, iniciativas, no âmbito da gestão municipal, voltadas para produção de material didático, reestruturação curricular, formação dos docentes e apoio às crianças com defasagem de aprendizagem. Ainda, há referências a ações desencadeadas no âmbito das escolas, reiterando o que se evidenciou nos estudos anteriormente citados neste artigo, sendo mencionado pela autora que, em duas das quatro escolas abrangidas pelo estudo, observaram-se organização de conteúdos, atividades e provas tendo como referência os instrumentos utilizados em avaliações externas.

Werle, Thum e Andrade (2009) analisam como a avaliação de larga escala se apresenta em municípios do Rio Grande do Sul. Embora a maioria dos municípios não tenha instituído normatização específica sobre o assunto, há registros de interações de municípios e de escolas daquele estado com resultados de avaliações externas e em larga escala, que ilustram iniciativas locais de uso dos resultados das avaliações, em especial, para formação de profissionais da educação, o que permite supor que, a despeito de exigências legais, a avaliação adentra a gestão municipal e das escolas.

A pesquisa de Ovando (2011) traz indícios de um movimento de implantação de sistemas próprios de avaliação por municípios de Mato Grosso do Sul. Entre os resultados desta investigação, destacam-se: a gradual incorporação, pelos gestores e educadores das redes, de resultados de avaliações externas nas decisões relativas à educação municipal, tendo o Índice de Desenvolvimento da Educação Básica (Ideb) se constituído em fator indutor de maior atenção aos resultados de desempenho de alunos, em especial na Prova Brasil; e a tendência dos municípios de formularem procedimentos próprios para avaliação da proficiência dos alunos.

Sousa, Pimenta e Machado (2012) analisam características de iniciativas de avaliação que vêm sendo implementadas em 14 redes municipais de ensino paulistas: Barrinha, Barueri, Brotas, Cajuru, Catanduva, Indaiatuba, Itanhaém, 
Jardinópolis, Lorena, Marília, Santa Bárbara d’Oeste, São José dos Campos, Porto Ferreira e Valparaíso. Com base em informações coletadas por meio de entrevistas com os profissionais das secretarias de educação e de documentos produzidos pelas redes sobre seus sistemas de avaliação, o estudo explora os usos que vêm sendo feitos dos resultados das avaliações para formulação e implementação das políticas educacionais municipais e eventuais relações ou articulações com as avaliações conduzidas pelo governo federal. Entre outras evidências, a investigação aponta que a avaliação vem sendo assumida, por gestores das redes e por seus profissionais, como instrumento de monitoramento e controle do ensino fundamental, atribuindo à iniciativa local maior poder de subsidiar decisões, em comparação com os elementos trazidos pelas avaliações conduzidas pelo governo federal, em especial a Prova Brasil.

Alavarse, Machado e Bravo (2013) também abordam a implantação de sistemas municipais de avaliação externa em quatro municípios paulistas - Cajuru, Catanduva, Porto Ferreira e Itanhaém -, explorando indicações sobre uso dos resultados das avaliações e seu potencial de incidir positivamente na qualidade do ensino, no sentido de subsidiar o acompanhamento do desenvolvimento de alunos e escola e a tomada de decisões, inclusive com a participação dos diversos segmentos que compõem as redes. No entanto, os autores alertam para efeitos deletérios, em especial, quando se transferem responsabilidades, pelos resultados, de gestores para professores.

Com propósito similar, Gimenes et al. (2013) discutem resultados de pesquisa sobre os usos das avaliações externas, no âmbito de quatro sistemas de ensino público do país que implantaram sistemas próprios de avaliação em larga escala: a rede estadual do Espírito Santo e as redes municipais de São Paulo (SP), Sorocaba (SP) e Castro (PR). O estudo analisa os objetivos e as justificativas das Secretarias de Educação para criação de sistemas próprios de avaliação e realça, entre outras conclusões, o potencial pedagógico dessas iniciativas para subsidiar o trabalho escolar. Outras considerações sobre as realidades municipais no tocante à avaliação externa e 
3 Esse estudo considera que a avaliação educacional é composta por diversas dimensões, a saber: avaliação de alunos; avaliação institucional; avaliação de profissionais da educação; e outras avaliações propostas em esfera municipal. Como avaliação de alunos entendem-se as iniciativas de coleta de evidências de desempenho dos alunos nas disciplinas escolares. por meio de provas, bem como de outras evidências sobre sua interação no processo escolar, sendo abertas possibilidades de serem mencionados, para além de provas, outros procedimentos. A avaliação institucional é entendida como a existência de proposta da rede municipal de ensino que solicite às escolas a realização de sua avaliação, contemplando possibilidades de autoavaliação e/ou de uso de informações resultantes de avaliações externas. Finalmente, a dimensão de avaliação de professores buscou captar iniciativas de avaliação de professores e de gestores implantadas pela rede municipal, buscando conhecer o que é avaliado e os procedimentos para essa avaliação. em larga escala podem ser encontradas em Gewehr (2010), Marinho (2010) e Nascimento (2010).

Além de pesquisas que procuram identificar possíveis efeitos das avaliações externas no contexto da gestão educacional de redes de ensino, tanto estaduais quanto municipais, como as referenciadas anteriormente neste artigo, há estudos que buscam apreender repercussões de avaliações no âmbito da escola, explorando seus usos e repercussões no planejamento e nas práticas escolares. Usualmente, tais trabalhos caracterizam-se por serem estudos de caso, cujas evidências trazidas têm como base depoimentos de profissionais que atuam nas escolas, complementados, algumas vezes, por observações. As contribuições desses estudos têm revelado convergência em iniciativas de organizar as propostas de ensino de acordo com as habilidades e conteúdos elencados em matrizes de referência de elaboração das provas e preocupação de preparar os alunos para obtenção de bons desempenhos nas provas. A título de indicar alguns estudos dessa natureza, citam-se, para ilustrar, Assunção (2013), Carvalho (2010), Côco (2014), Duarte, (2014), Gomes (2009), Graça (2010), Horta Neto (2006), Madergan (2014), Pimenta (2012), Prust (1999), Rahal (2010), Rocha (2013), Silva (2005) e Souza (2009).

Em seu conjunto, os estudos consultados permitem constatar que, desde os anos 2000, estados e municípios vêm pouco a pouco assimilando o modelo de gestão da educação pública implantado pelo governo federal a partir da década de 1990, com o crescente uso dos resultados das avaliações em larga escala como principal indicador de qualidade. No entanto, tais estudos não possibilitam compreender até que ponto esse modelo de gestão tem sido adotado pela totalidade dos municípios brasileiros, nem identificar apropriações alternativas da lógica da avaliação em larga escala por esses entes federados.

Embora reconhecendo o desafio de se desenvolver uma pesquisa em âmbito nacional, tanto pela sua abrangência quanto pela sua complexidade, que busque retratar tendências, especificidades e diversidades de iniciativas relacionadas à avaliação educacional ${ }^{3}$ em andamento nos 5.568 
municípios do território nacional, delineou-se um estudo que teve como propósitos caracterizar iniciativas de avaliação de municípios brasileiros, no que se refere à sua abrangência, aos seus objetivos e ao desenho metodológico, e analisar tendências de políticas educacionais e ações municipais que se apoiem em resultados de avaliações existentes.

Não se conta ainda com uma pesquisa com este escopo e é nessa lacuna que se situam as contribuições trazidas no presente artigo que, além desta introdução, apresenta informações sobre os procedimentos de coleta de dados adotados no estudo e discute alguns de seus resultados.

Como destacado anteriormente, neste texto as evidências trazidas pela pesquisa são tratadas em uma abordagem descritiva, cumprindo o objetivo de apresentar um mapeamento de revelações propiciadas pelas manifestações obtidas de 4.309 municípios do país $(77,4 \%$ do total) que participaram da primeira etapa da pesquisa, com ênfase na avaliação de alunos. Assim, apesar de outras dimensões da avaliação terem sido pesquisadas, elas não serão tratadas neste artigo, tendo em conta a extensão das informações coletadas.

\section{PROCEDIMENTOS DE ESTUDO}

O mapeamento das iniciativas municipais se deu por meio de survey, com o objetivo de obter informações sobre a existência ou não de avaliações externas próprias dos municípios, identificando os motivos que justificaram sua criação ou aquisição e seus delineamentos metodológicos. Além disso, buscou-se identificar usos dos resultados das avaliações, tanto federais como estaduais e municipais, na gestão educacional dos municípios.

O envio de link para o questionário eletrônico foi antecedido por ligações telefônicas para todos os secretários municipais de educação, com o objetivo de sensibilizá-los para a importância da pesquisa, tendo-se conseguido contato com 5.532, o que representa $99 \%$ do total. Nesses contatos, realizados entre abril e maio de 2014 por equipes especialmente treinadas, foi explicado, a cada dirigente, o propósito da pesquisa, perguntado sobre seu interesse em participar 
desse esforço e, em caso afirmativo, solicitado um endereço de e-mail para o qual deveria ser enviado o instrumento de coleta de informações. Durante os meses seguintes foi feito um acompanhamento da evolução das respostas e, quando necessários, foram efetuados outros telefonemas para reforçar a importância da pesquisa e, eventualmente, obter novos endereços eletrônicos para o reenvio da ferramenta. Em fins de setembro, encerrou-se a coleta das informações.

Os questionários, em formato eletrônico, foram construídos e aplicados utilizando-se a ferramenta Survey Monkey. Esse software, além de fazer a coleta de dados, codifica-os e consolida-os em um banco de dados, base para os processamentos realizados neste trabalho.

Para atender aos objetivos da pesquisa, o questionário foi estruturado em quatro dimensões: identificação do município; avaliações existentes na rede municipal; avaliações propostas pela rede municipal (com questões sobre avaliação de alunos, institucional, de docentes, de gestores e outro tipo de avaliação); e caracterização dos usos das avaliações. No total, foram apresentados 44 itens, abertos e de respostas construídas. Conforme o padrão de respostas fornecidas pelos respondentes, alguns dos itens podiam ou não ser apresentados ao respondente. Assim, por exemplo, caso não fosse assinalado que o município realizava avaliação de alunos, os itens que tratavam dessa dimensão avaliativa não eram apresentados ao respondente, que era redirecionado para o bloco de questões seguintes, sobre outras dimensões avaliativas. Reitera-se que o presente texto trata de iniciativas de avaliação externa de alunos, identificadas por meio do estudo, não abrangendo, portanto, todas as dimensões investigadas.

\section{RESULTADOS}

Primeiramente, cabe destacar a abrangência da pesquisa. Dos 5.532 municípios efetivamente contatados por telefone e/ou e-mail, 4.309 responderam ao survey. Esses municípios diferem, em algumas características, daqueles que preferiram não participar da pesquisa ( $\mathrm{N}=1.223)$. Tais diferenças são 
significativas $(p$-value $\leq 0,05)$ no que se refere aos dados populacionais, ao IDHM, ${ }^{4}$ ao número de escolas municipais, ao PIB (Produto Interno Bruto) per capita e à cobertura da rede municipal (\% de escolas municipais sobre o total de escolas do município). Cabe ressalvar, no entanto, que ainda que o teste estatístico tenha sido significativo para o IDHM, os valores médios dessa variável para os municípios respondentes e os não respondentes situam-se na mesma faixa, ou seja, os municípios pertencem, em geral, ao grupo de médio desenvolvimento humano.
4 I Índice de Desenvolvimento Humano é um indicador que permite conhecer a realidade do desenvolvimento humano do território brasileiro, contemplando dimensões que não se restringem à ideia de desenvolvimento como crescimento econômico: educação, longevidade e renda. As faixas de IDHM e seus respectivos significados são: entre $\mathrm{O}$ e 0,499 (muito baixo desenvolvimento humano); entre 0,500 e 0,599 (baixo desenvolvimento humano); entre 0,600 e 0,699 (médio desenvolvimento humano); entre 0,700 e 0,799 (alto desenvolvimento humano); entre 0,800 e 1 (muito alto desenvolvimento humano) (Fonte: Atlas do Desenvolvimento Humano. Disponive/ em: <http://www.atlasbrasil. org.br/2013/>. Acesso em: mar. 2015)

TABELA 1: Características gerais dos municípios que responderam e dos que não responderam à pesquisa

\begin{tabular}{|c|c|c|c|c|}
\hline VARIÁVEIS DE CONTEXTO & $\begin{array}{l}\text { GRUPO DE } \\
\text { MUNICÍPIOS }\end{array}$ & $\mathbf{N}$ & MÉDIA & D.P. \\
\hline \multirow{2}{*}{$\begin{array}{l}\text { População em janeiro de } 2013 \\
\text { (TCU) }\end{array}$} & respondentes & 4.309 & 38.024 & 234.321 \\
\hline & não respondentes & 1.223 & 27.257 & 78.561 \\
\hline \multirow{2}{*}{ PIB per capita 2011} & respondentes & 4.304 & 14.705 & 15.856 \\
\hline & não respondentes & 1.223 & 12.396 & 14.791 \\
\hline \multirow{2}{*}{ IDHM 2010} & respondentes & 4.304 & 0,664 & 0,071 \\
\hline & não respondentes & 1.223 & 0,642 & 0,071 \\
\hline \multirow{2}{*}{ Número de escolas municipais } & respondentes & 4.308 & 30,3 & 48,9 \\
\hline & não respondentes & 1.223 & 35,3 & 41,8 \\
\hline \multirow{2}{*}{$\begin{array}{l}\text { Cobertura da rede municipal } \\
\text { (\% com relação ao total) }\end{array}$} & respondentes & 4.308 & 71,7 & 18,1 \\
\hline & não respondentes & 1.223 & 75,7 & 17,1 \\
\hline \multirow{2}{*}{ Fundeb 2013} & respondentes & 4.304 & 11.900 .169 & 61.398 .432 \\
\hline & não respondentes & 1.223 & 10.191 .385 & 21.444 .757 \\
\hline
\end{tabular}

Fonte: Elaboração dos autores.

A apreciação dos valores de desvio-padrão para cada variável permite destacar que é preciso ter o cuidado de se assumir uma perspectiva de análise que realce as especificidades que marcam as iniciativas em curso no país, principalmente no que se refere às ações propostas dos municípios, que possuem realidades diversas e desiguais em relação às suas características físicas, econômicas, socioculturais e, consequentemente, educacionais (SOUSA, 2013).

As informações que se seguem referem-se aos municípios respondentes. Em termos regionais, a distribuição de respostas pode ser observada na Tabela $2 .{ }^{5}$
5 Agradecemos a Raquel Cunha Valle, estatística da Fundação Carlos Chagas, pelo processamento e revisão dos dados utilizados neste trabalho. 
TABELA 2: Percentual de municípios que responderam ao survey, por região

\begin{tabular}{l|c:c}
\hline REGIÃO & MUNICÍPIOS BRASIL & MUNICÍPIOS RESPONDENTES (\%) \\
\hline Norte & 450 & 71,8 \\
\hline Nordeste & 1.793 & 69,0 \\
\hline Centro-Oeste & 466 & 79,8 \\
\hline Sudeste & 1.668 & 83,6 \\
\hline Sul & 1.191 & 82,5 \\
\hline Total & $\mathbf{5 . 5 6 8}$ & $\mathbf{7 7 , 4}$ \\
\hline
\end{tabular}

Fonte: Elaboração dos autores.

Segundo o percentual de respostas obtidas, nota-se maior receptividade à pesquisa nas regiões Centro-Oeste, Sudeste e Sul, com $80 \%$ ou mais de retorno dos municípios. No Norte e Nordeste, a participação foi próxima a 70\%, percentual relevante para esse tipo de pesquisa. Com base no retorno alcançado, acredita-se que esse quantitativo de respostas suporta afirmações quanto às tendências dominantes nos municípios em relação à sua interação com avaliações em larga escala.

Considerando-se o porte populacional dos 4.309 municípios que responderam à pesquisa, verifica-se que são entes de tamanhos variados (Tabela 3). Cerca de $87 \%$ dos maiores municípios brasileiros (com mais de 500.000 habitantes) responderam à pesquisa. Como pode ser observado na Tabela 3 , foram obtidas respostas de mais de $70 \%$ dos municípios em todas as faixas de porte populacional, o que permite afirmar que os dados coletados são representativos da diversidade populacional dos municípios brasileiros.

TABELA 3: Percentual de municípios participantes da pesquisa, segundo o porte

\begin{tabular}{l|c:c:c}
\hline NÚMERO DE HABITANTES & $\begin{array}{c}\text { MUNICÍPIOS } \\
\text { BRASIL }\end{array}$ & $\begin{array}{c}\text { MUNICÍPIOS } \\
\text { RESPONDENTES }\end{array}$ & $\begin{array}{c}\text { \% DE } \\
\text { RESPONDENTES }\end{array}$ \\
\hline até 5.000 & 1.246 & 984 & 79,0 \\
\hline 5.001 a 10.000 & 1.226 & 975 & 79,5 \\
\hline 10.001 a 20.000 & 1.378 & 1.052 & 76,3 \\
\hline 20.001 a 50.000 & 1.081 & 790 & 73,1 \\
\hline 50.001 a 100.000 & 340 & 261 & 76,8 \\
\hline 100.001 a 500.000 & 259 & 214 & 82,6 \\
\hline mais de 500.000 & 38 & 33 & 86,8 \\
\hline Total & $\mathbf{5 . 5 6 8}$ & $\mathbf{4 . 3 0 9}$ & $\mathbf{7 7 , 4}$ \\
\hline
\end{tabular}

Fonte: Elaboração dos autores. 
Os municípios indicaram uma expressiva participação na Prova Brasil ${ }^{6}$ e na Avaliação Nacional de Alfabetização (ANA) ${ }^{7}$ (Gráficos 1 e 2), o que é esperado, considerando-se a possibilidade de acesso a verbas e a programas federais pelos municípios que participam desses testes coordenados pelo Inep.

É possível supor que a indicação de não participação de 261 municípios na ANA (6\%) e de 265 na Prova Brasil (6\%) seja em decorrência dos critérios estabelecidos pelo Inep para a realização desses testes.

6 Sobre a Prova Brasil, consultar a Portaria n. 304, de 21 de junho de 2013, e Inep. Saeb, disponível em: $<$ http://portal.inep.gov.br/web/saeb/ aneb-e-anresc $>$, acesso em: 18 jun. 2014.

7 Sobre a Avaliação Nacional da Alfabetização (ANA), consultar a Portaria n. 304, de 21 de junho de 2013, e Inep. ANA, disponível em: $<$ http://portal.inep.gov.br/web/saeb/ ana>, acesso em: 18 jun. 2014

\section{GRÁFICO 1: Municípios participantes da Prova Brasil}

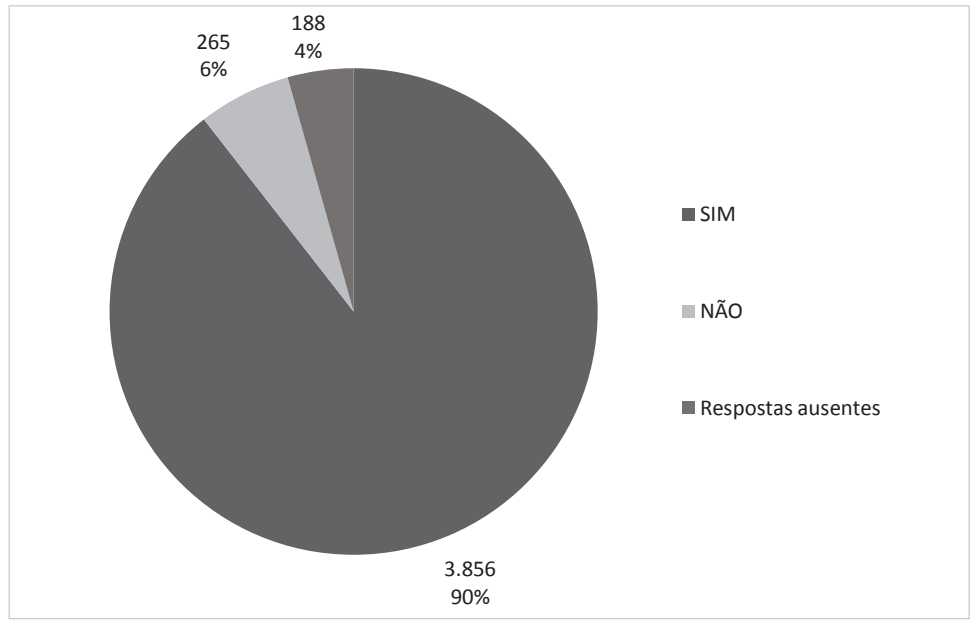

Fonte: Elaboração dos autores.

GRÁFICO 2: Municípios participantes da ANA

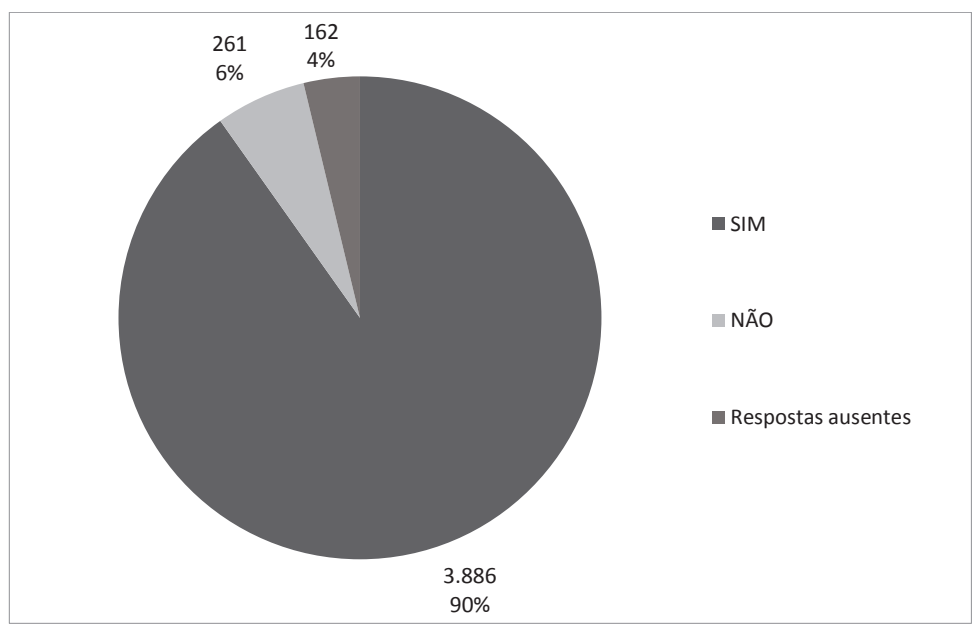

Fonte: Elaboração dos autores. 
Observa-se, ainda, que 4.187 dos municípios responden-

8 Conforme consta da página do Inep, a Avaliação da Alfabetização Infantil - Provinha Brasil é um teste de característica diagnóstica com o objetivo de investigar desenvolvimento das habilidades relativas à alfabetização e ao letramento em Língua Portuguesa e Matemática, para crianças matriculadas no $2^{\circ}$ ano do ensino fundamental das escolas públicas brasileiras. Aplicado duas vezes ao ano (no início e no final do período letivo), o teste é dirigido aos alunos que passaram por, pelo menos, um ano escolar dedicado ao processo de alfabetização. A adesão ao teste é opcional e a aplicação fica a critério de cada Secretaria de Educação das unidades federadas. Disponíve em: <http://portal.inep.gov.br/web/ provinha-brasil/apresentacao> Acesso em: 15 jun. 2014 tes (97\%) assinalaram adesão à Provinha Brasil ${ }^{8}$ (Gráfico 3) Cabe destacar que a participação nessa avaliação não condiciona o acesso a programas federais, como no caso anterior.

\section{GRÁFICO 3: Municípios participantes da Provinha Brasil}

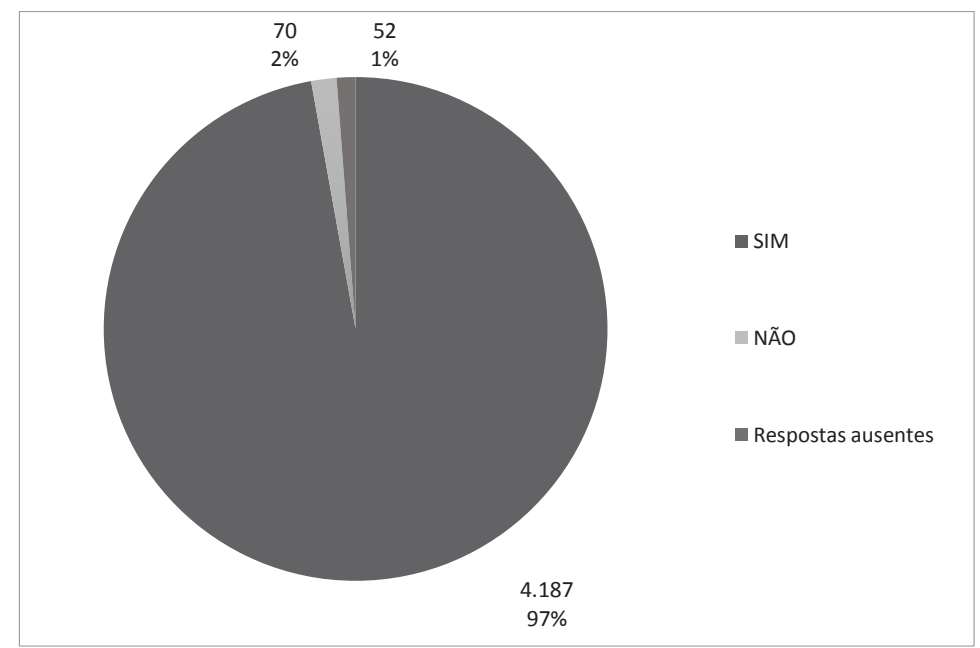

Fonte: Elaboração dos autores

Além da participação em testes aplicados pelo Inep, observa-se que $67 \%$ dos municípios indicaram aderir, também, a avaliações externas implementadas pelos governos estaduais, como ilustrado no Gráfico 4. 
GRÁFICO 4: Participação dos municípios em avaliações estaduais

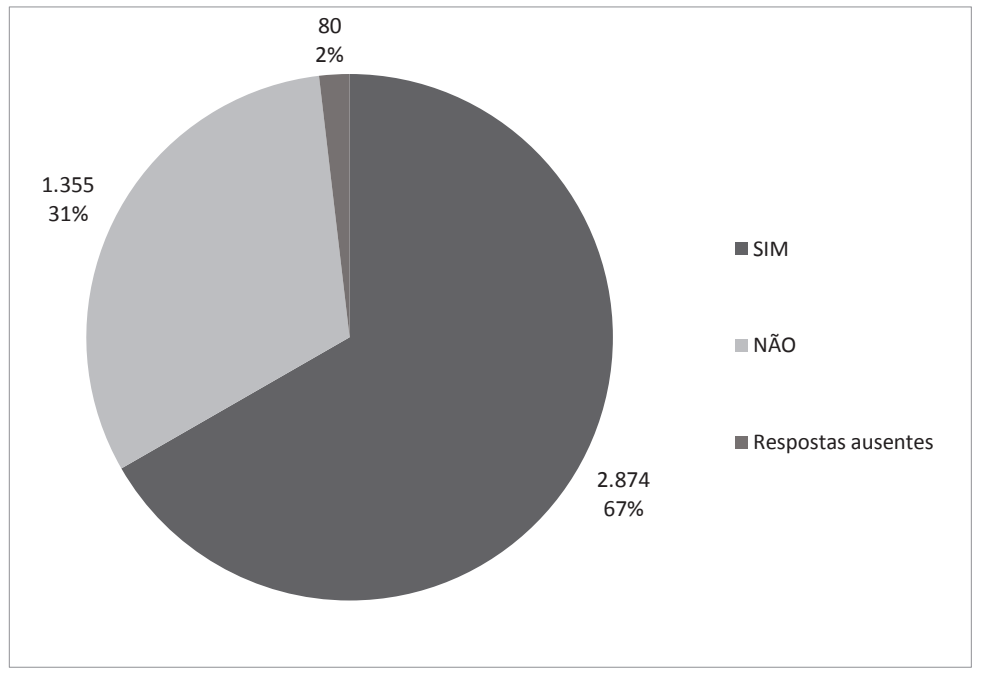

Fonte: Elaboração dos autores.

Outro indício do grau de mobilização dos municípios em favor dos testes elaborados pelo governo federal e/ou governos estaduais foi obtido por meio de duas indagações apresentadas no questionário. A primeira questionava se a Secretaria Municipal estimula as escolas a prepararem seus alunos para esses testes, obtendo-se resposta positiva de $82 \%$ dos respondentes. A segunda referia-se à aplicação de provas, pela Secretaria Municipal, com o objetivo de preparar os alunos para os testes, para a qual se obtiveram $57 \%$ de respostas afirmativas.

Uma questão central para a pesquisa indagava se existiam ou não avaliações próprias conduzidas pelos municípios; os percentuais de respostas podem ser visualizados no Gráfico 5. 
GRÁFICO 5: Municípios com avaliações próprias

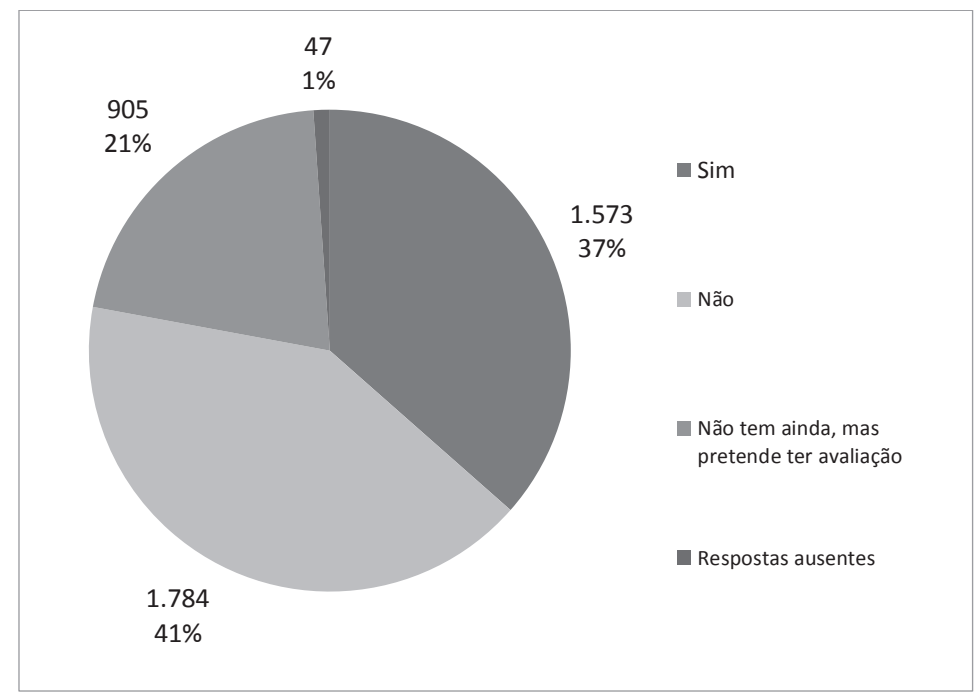

Fonte: Elaboração dos autores

Além dos 1.573 municípios que informaram possuir avaliações próprias (37\% dos respondentes), 905 (21\% dos respondentes) declararam pretender ter uma avaliação. Portanto, com cerca de $60 \%$ do total de municípios possuindo uma avaliação, ou com a intenção de construí-la, pode-se afirmar que as avaliações em larga escala parecem cada vez mais legitimadas no âmbito das gestões municipais.

Para conhecer melhor o movimento de criação das avaliações municipais ao longo do tempo, foi perguntado aos gestores municipais qual o ano de implantação das iniciativas. Dos 1.573 municípios que declararam ter, em 2014, avaliação própria, 1.383 registraram essa informação, conforme dados da Tabela 4.

Ainda que a primeira iniciativa date do início da década de 1980, observa-se que é a partir de 2005 que as avaliações propostas por municípios se expandem. Assim, até 2004, havia 103 municípios com ações próprias de avaliação e, de 2005 a 2013, acrescem-se a esse número 1.280 novas iniciativas, além de avaliações que podem estar sendo implantadas depois de setembro de 2014, data de encerramento da coleta de dados. Vale investigar se esse aumento foi, de algum modo, induzido pela implantação da Prova Brasil e do Ideb. 
Além disso, uma nova ampliação do número de municípios aplicando suas avaliações coincide com a eleição dos atuais prefeitos, em 2012.

TABELA 4: Número de municípios com avaliações próprias de acordo com o ano de sua implantação

\begin{tabular}{|c|c|c|}
\hline ANO & $\mathrm{N}$ & $\%$ \\
\hline Anterior a 2000 & 34 & 2,2 \\
\hline 2000 & 25 & 1,6 \\
\hline 2001 & 9 & 0,6 \\
\hline 2002 & 14 & 0,9 \\
\hline 2003 & 11 & 0,7 \\
\hline 2004 & 10 & 0,6 \\
\hline 2005 & 59 & 3,8 \\
\hline 2006 & 39 & 2,5 \\
\hline 2007 & 55 & 3,5 \\
\hline 2008 & 64 & 4,1 \\
\hline 2009 & 163 & 10,4 \\
\hline 2010 & 147 & 9,3 \\
\hline 2011 & 107 & 6,8 \\
\hline 2012 & 104 & 6,6 \\
\hline 2013 & 436 & 27,7 \\
\hline 2014 & 106 & 6,7 \\
\hline Sem informação & 190 & 12,1 \\
\hline Total & 1.573 & 100,0 \\
\hline
\end{tabular}

Fonte: Elaboração dos autores.

Com o intuito de saber a forma como as avaliações municipais estavam institucionalizadas na administração municipal, perguntou-se sobre a existência de regulamentação dessa ação e qual seria a norma legal que a instituiu. As respostas indicam que apenas 249 municípios (16\%) possuem algum tipo de regulamentação para a avaliação que realizam, embora nem todos tenham especificado qual é a normatização que a regulamenta. Entre os municípios que realizam algum tipo de avaliação, 1.173 (74\%) afirmaram que essa avaliação não está regulamentada e 151 (10\%) não responderam à questão. Esse resultado permite afirmar que a realização de avaliações próprias antecede à sua formalização legal. 
Em relação às características gerais dos municípios que declararam possuir avaliação própria, percebe-se, pela análise da Tabela 5, que estas são muito diferentes daquelas apresentadas pelos municípios que não possuem esse tipo de avaliação (ou não responderam à questão). Em geral, os municípios que têm alguma proposta de avaliação própria são mais populosos e com maior PIB per capita. Nota-se que eles recebem um valor de Fundo de Manutenção e Desenvolvimento da Educação Básica e de Valorização dos Profissionais da Educação (Fundeb) superior ao daqueles que não possuem proposta própria de avaliação e o número de escolas, nesses municípios, é um pouco maior do que nos demais.

\begin{tabular}{|c|c|c|c|c|}
\hline VARIÁVEIS DE CONTEXTO & GRUPO DE MUNICÍPIOS & $\mathbf{N}$ & MÉDIA & D.P. \\
\hline \multirow{2}{*}{$\begin{array}{l}\text { População em janeiro de } 2013 \\
\text { (TCU) }\end{array}$} & Possui avaliação própria & 1.573 & 55.487 & 374.087 \\
\hline & Não possui ou resposta ausente & 2.736 & 27.984 & 75.990 \\
\hline \multirow{2}{*}{ PIB per capita 2011} & Possui avaliação própria & 1.572 & 15.629 & 17.886 \\
\hline & Não possui ou resposta ausente & 2.732 & 14.173 & 14.538 \\
\hline \multirow{2}{*}{ IDHM 2010} & Possui avaliação própria & 1.572 & 0,670 & 0,069 \\
\hline & Não possui ou resposta ausente & 2.732 & 0,661 & 0,072 \\
\hline \multirow{2}{*}{ Número de escolas municipais } & Possui avaliação própria & 1.573 & 32,9 & 67,0 \\
\hline & Não possui ou resposta ausente & 2.735 & 28,8 & 34,4 \\
\hline \multirow{2}{*}{$\begin{array}{l}\text { Cobertura da rede municipal } \\
\text { (\% com relação ao total) }\end{array}$} & Possui avaliação própria & 1.573 & 70,3 & 18,3 \\
\hline & Não possui ou resposta ausente & 2.735 & 72,6 & 17,9 \\
\hline \multirow{2}{*}{ Fundeb 2013} & Possui avaliação própria & 1.572 & 16.301 .694 & 98.232 .915 \\
\hline & Não possui ou resposta ausente & 2.732 & 9.367 .520 & 19.265 .559 \\
\hline
\end{tabular}

Indagando-se sobre as razões que levaram a rede municipal de ensino a implantar avaliações próprias dos alunos, foram obtidas respostas que revelam, ao que parece, a crença de que tal iniciativa pode induzir à melhoria de qualidade do ensino, sendo necessário investigar com maior profundidade o significado dessa qualidade. Outras razões apresentadas parecem referir-se à necessidade de diagnóstico e monitoramento das aprendizagens. Nessa perspectiva, cabe notar 
que as indicações registradas convergem para iniciativas no âmbito das escolas, sejam aquelas voltadas para o diagnóstico de proficiências dos alunos, sejam as direcionadas para acompanhar e aprimorar a prática pedagógica e orientar a formação continuada.

Também foram indicadas motivações relacionadas ao gerenciamento educacional, por meio da implantação de estratégias de responsabilização, controle e prestação de contas. Por fim, destacam-se razões relativas à melhoria de índices educacionais, como fluxo, evasão e repetência, havendo, também, referências explícitas ao aumento do Ideb e/ou alcance de metas. No caso do Ideb, seu uso pelos municípios pode estar relacionado a programas do MEC, como o Plano de Desenvolvimento da Escola (PDE-Escola), que visa ao apoio à gestão escolar, e os Planos de Ações Articuladas (PAR). ${ }^{9}$

No que se refere a quem vem participando da concepção das avaliações conduzidas pelos municípios, considerando-se as respostas válidas, houve menção, pela maioria dos respondentes, à participação de professores, técnicos da Secretaria de Educação e gestores da rede, o que indica, nesses casos, tendência de envolvimento dos profissionais da rede em seu delineamento. Nota-se, também, que municípios vêm recorrendo a assessorias externas (consultorias independentes, empresas ou universidades) para definição do sistema adotado, conforme dados do Gráfico 6.
9 Plano de Desenvolvimento da Educação (PDE), apresentado pelo Ministério da Educação em 2007, disponibilizou aos estados e municípios instrumentos de avaliação e implementação de políticas de melhoria da qualidade da educação básica, tendo como programa estratégico o Plano de Metas Compromisso Todos pela Educação. Com base no Plano de Metas, os estados e municípios passaram à elaboração do seu Plano de Ações Articuladas (PAR), o qual contempla o diagnóstico da situação educacional local e a elaboração do planejamento para o período 2011 a 2014, com base no Ideb de 2005, 2007 e 2009. 
GRÁFICO 6: Proporção da participação de diferentes agentes na concepção das avaliações promovidas pelas redes municipais de ensino

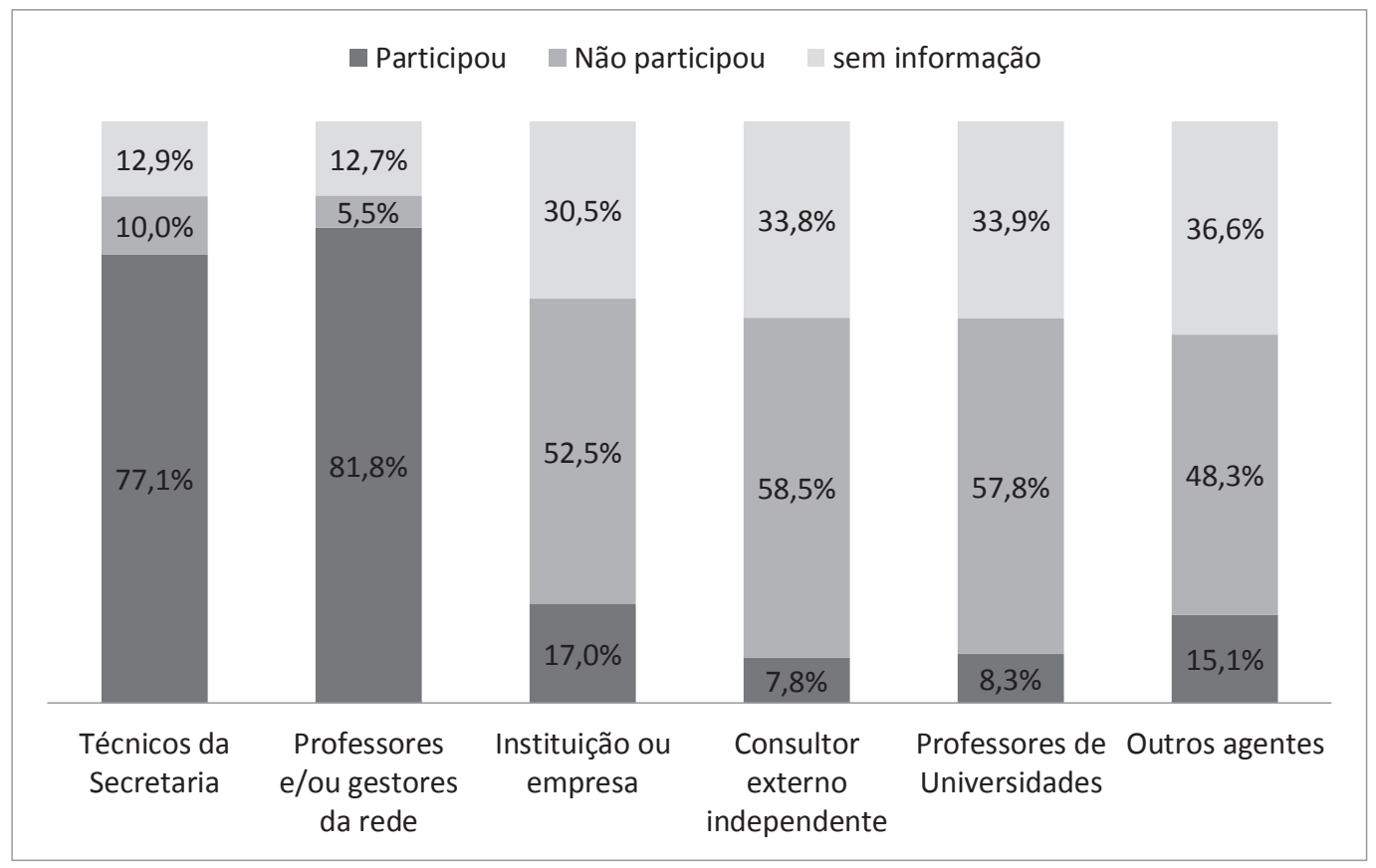

Fonte: Elaboração dos autores.

Quanto aos usos dos resultados das avaliações, foram apresentadas aos respondentes alternativas de respostas, solicitando que assinalassem aquelas que correspondiam às práticas municipais usuais, podendo ser indicada mais de uma alternativa.

Para facilitar a análise, as respostas foram agrupadas em cinco grupos de usos, relacionados: a algum tipo de mobilização da escola (Tabela 6); a ações ou programas educacionais das secretarias municipais (Tabela 7); ao monitoramento da rede de ensino (Tabela 8); ao apoio à gestão de pessoal (Tabela 9); e à divulgação de informações para diferentes públicos (Tabela 10). Os dados obtidos referem-se ao percentual de respostas afirmativas dentro do universo de respondentes $(\mathrm{N}=4.309)$.

A partir dos dados da Tabela 6, destaca-se que $91 \%$ dos respondentes assinalaram que procuram motivar as escolas a buscarem melhores resultados e $88 \%$ informaram que estimulam as escolas para que discutam seus resultados. 
TABELA 6: Proporção de municípios que utilizam os resultados das avaliações em iniciativas relacionadas a algum tipo de mobilização das escolas

\begin{tabular}{l|c}
\hline INICIATIVAS & $\begin{array}{c}\text { \% DE RESPOSTAS } \\
\text { AFIRMATIVAS }\end{array}$ \\
\hline Motivar as escolas a buscarem melhores resultados & 91,3 \\
\hline Estimular as escolas a discutirem os resultados obtidos & 88,0 \\
\hline Propor que as escolas produzam relatório explicativo dos resultados obtidos & 47,0 \\
\hline
\end{tabular}

Fonte: Elaboração dos autores.

A Tabela 7 apresenta as respostas agrupadas em torno de usos relacionados a ações ou programas educacionais das secretarias municipais.

TABELA 7: Proporção de municípios que utilizam os resultados das avaliações em iniciativas relacionadas a ações ou programas educacionais das secretarias municipais

\begin{tabular}{l|c}
\hline INICIATIVAS & $\begin{array}{c}\text { \% DE RESPOSTAS } \\
\text { AFIRMATIVAS }\end{array}$ \\
\hline Avaliar programas e ações desenvolvidos pela Secretaria & 79,2 \\
\hline Reestruturar o currículo das escolas & 72,7 \\
\hline Desenvolver material didático & 64,1 \\
\hline Reformular o Plano Municipal de Educação & 61,5 \\
\hline Comprar material curricular estruturado e/ou apostilado & 36,7 \\
\hline Dar algum prêmio aos alunos (computador, viagem, etc.) & 13,3 \\
\hline Dar algum prêmio às escolas (computadores, recursos financeiros, etc.) & 9,5 \\
\hline Oferecer bônus salarial aos profissionais das escolas & 6,3 \\
\hline
\end{tabular}

Fonte: Elaboração dos autores.

As alternativas mais assinaladas, conforme dados da Tabela 7, apontam para o uso dos resultados para avaliar programas e ações desenvolvidos pela Secretaria (79\%) e para reestruturar o currículo das escolas (73\%). Outros usos destacados - desenvolver material didático (64\%) e reformular o Plano Municipal de Educação (62\%) - indicam ações no sentido de dar consequência ao processo de avaliação e, possivelmente, uma preocupação de agir sobre a realidade, visando superar possíveis problemas encontrados, com base nos resultados obtidos. Destaca-se que a assertiva que trata 
da compra de material curricular estruturado e/ou apostilado foi assinalada por $37 \%$ dos respondentes. A estratégia de premiar alunos em função de resultados obtidos nos testes foi indicada por $13 \%$ dos respondentes. Ainda com relação à premiação, $10 \%$ dos respondentes informaram que oferecem prêmios às escolas e $6 \%$ proporcionam bônus salarial aos profissionais das escolas. Nesses casos, parece estar subjacente à crença de que associar estímulos aos resultados dos testes pode induzir à melhoria do processo educacional.

Os dados disponibilizados na Tabela 8 reiteram a preocupação de monitorar as escolas, a qual já havia sido destacada quando os respondentes apontaram espontaneamente as razões que levaram a rede municipal de ensino a implantar avaliações próprias dos alunos. As três alternativas mais assinaladas nesse grupo foram: identificar carências das escolas da rede; propor intervenções diferenciadas nas escolas; e diagnosticar desigualdades entre as escolas da rede. Destacase, ainda, que $63 \%$ dos respondentes assinalaram que usam as avaliações para estabelecer metas de desempenho para as escolas, além daquelas fixadas pelo Ideb, podendo significar um aumento da pressão sobre a escola para atingir metas definidas pela gestão municipal. Além disso, $12 \%$ dos respondentes indicaram que utilizam os dados das avaliações para remanejar alunos entre escolas da rede, fato que merece ser mais bem investigado.

TABELA 8: Proporção de municípios que utilizam os resultados das avaliações em iniciativas relacionadas ao monitoramento da rede de ensino

\begin{tabular}{l|c}
\hline INICIATIVAS & $\begin{array}{c}\text { \% DE RESPOSTAS } \\
\text { AFIRMATIVAS }\end{array}$ \\
\hline Identificar carências das escolas da rede & 84,5 \\
\hline Propor intervenções diferenciadas nas escolas & 83,0 \\
\hline Diagnosticar desigualdades entre as escolas da rede & 62,9 \\
\hline Estabelecer metas de desempenho para as escolas, além daquelas fixadas pelo ldeb & 62,7 \\
\hline Remanejar alunos entre as escolas da rede & 11,9 \\
\hline
\end{tabular}

Fonte: Elaboração dos autores. 
A partir dos dados da Tabela 9, observa-se uma tendência dos gestores de declarar que os resultados das avaliações são utilizados para planejar a formação continuada dos profissionais da rede. O que se pode investigar é o sentido assumido nessa formação: se o seu objetivo é fornecer aos profissionais estratégias para treinar os alunos para as próximas avaliações, ou aprimorar aspectos da formação que tenham sido identificados como falhos com base nos resultados obtidos. As outras três assertivas relacionam-se a ações de gestão de pessoal, como remanejamento de professores entre escolas da rede $(21 \%)$, remanejamento de gestores $(11 \%)$ e demissão de gestores (6\%), ações que carecem de maior investigação, para se compreender o sentido que vêm assumindo na gestão educacional.

TABELA 9: Proporção de municípios que utilizam os resultados das avaliações em iniciativas relacionadas ao apoio da gestão de pessoal

\begin{tabular}{l|c}
\hline INICIATIVAS & $\begin{array}{c}\text { \% DE RESPOSTAS } \\
\text { AFIRMATIVAS }\end{array}$ \\
\hline Planejar a formação continuada dos profissionais da rede & 84,1 \\
\hline Remanejar professores entre as escolas da rede & 21,4 \\
\hline Remanejar gestores entre as escolas da rede & 11,4 \\
\hline Demitir gestores escolares & 6,0 \\
\hline
\end{tabular}

Fonte: Elaboração dos autores.

Por fim, a Tabela 10 traz dados a respeito dos usos relacionados à divulgação das informações para diferentes públicos. Os respondentes indicaram que um dos usos dos resultados refere-se ao fornecimento de informações sobre as escolas para as famílias e comunidade escolar (85\%), inclusive, por meio da colocação de placas em frente às escolas (23\%), ação polêmica que tem sido alvo de diversos questionamentos. 
TABELA 10: Proporção de municípios que utilizam os resultados das avaliações em iniciativas relacionadas à divulgação de informações para diferentes públicos

\begin{tabular}{l|c}
\hline INICIATIVAS & $\begin{array}{c}\text { \% DE RESPOSTAS } \\
\text { AFIRMATIVAS }\end{array}$ \\
\hline Fornecer informações sobre as escolas para as famílias e a comunidade escolar & 85,1 \\
\hline Colocar os resultados em uma placa visível na frente da escola & 22,6 \\
\hline
\end{tabular}

Fonte: Elaboração dos autores.

Vale destacar que as indicações quanto aos usos dos resultados das avaliações assinalados com maior frequência corroboram as razões apontadas para a sua criação, conforme indicado anteriormente. Note-se que as maiores frequências de resposta incidem em expectativas que apontam na direção de que os resultados venham a ser apropriados pelas escolas com o objetivo de aprimorar o trabalho escolar. Além disso, as iniciativas da Secretaria de Educação, ou instâncias de apoio a esta, relacionadas ao planejamento de intervenções na rede de ensino contam com maior incidência de respostas positivas. Também é destaque a prática de estabelecer metas de desempenho além daquelas fixadas pelo Ideb, apesar de não se ter informações sobre quais seriam elas e nem a forma como estariam sendo discutidas ou fixadas. De toda forma, essa informação indica que o estabelecimento de metas tem se transformado em um instrumento de gestão importante para as secretarias. Por outro lado, as respostas indicam que a associação de incentivos aos resultados das avaliações não constitui prática recorrente para os respondentes desta pesquisa.

\section{INDICAÇÕES FINAIS}

As informações sistematizadas neste texto possibilitam retratar, em linhas gerais, como vem se dando a relação de municípios com a avaliação em larga escala, suscitando pontos que merecem aprofundamento não só no âmbito deste estudo, mas de outros que se delinearem como complementares. São observados aspectos que indicam interseção com os resultados de pesquisas já concluídas que se voltaram a estudos de casos municipais, referenciadas no início deste artigo. 
As contribuições trazidas para discussão, relativas a contextos municipais, permitem evidenciar que a avaliação em larga escala vem se consolidando como instrumento de gestão educacional nas municipalidades. Há tendência de criação, pelos municípios, de propostas próprias de avaliação, além de aderência às iniciativas federais e estaduais.

Parece haver correspondência entre a crescente presença de iniciativas nesse âmbito de gestão e as ações do Ministério da Educação, sejam aquelas relativas à avaliação em larga escala, seja a criação de índice para se aquilatar o desenvolvimento da qualidade educacional.

\section{REFERÊNCIAS}

ALAVARSE, Ocimar Munhoz; MACHADO, Cristiane; BRAVO, Maria Helena. Avaliações externas e qualidade na educação básica: articulações e tendências. Estudos em Avaliação Educacional, São Paulo, v. 24, n. 54, p. 12-31, jan./abr. 2013.

ASSUNÇÃO, Mariza. F. O mito da virtuosidade da avaliação: trabalho docente e avaliações externas na educação básica. 2013. Tese (Doutorado em Educação) - Instituto de Ciências da Educação, Universidade Federal do Pará, Belém, 2013.

BAUER, Adriana. Estudos sobre Sistemas de Avaliação Educacional. Revista @mbienteeducação, São Paulo, v. 5, p. 7-31, 2012.

Avaliação de redes de ensino e gestão educacional: o que apontam os estudos acadêmicos. In: CONGRESSO IBERO-AMERICANO DE POLÍTICA E ADMINISTRAÇÃO DA EDUCAÇÃO, 4.; CONGRESSO LUSO BRASILEIRO DE POLÍTICA E ADMINISTRAÇÃO DA EDUCAÇÃO, 7., 2014, Portugal. Anais... Portugal, 2014. Disponível em: <http://www.anpae.org.br/IBERO_ AMERICANO_IV/GT2/GT2_Comunicacao/AdrianaBauer_GT2_integral.pdf $>$. Acesso em: 10 abr. 2015.

BAUER, Adriana; REIS, Adriana Teixeira. Balanço da produção teórica sobre avaliação de sistemas educacionais no Brasil: 1988 a 2011. In: REUNIÃO NACIONAL DA ANPED, 36., 2013, Goiânia - GO. Disponível em: < http:/| www.36reuniao.anped.org.br/pdfs_trabalhos_aprovados/gt05_trabalhos_ pdfs/gt05_3375_texto.pdf>. Acesso em: 10 jun. 2014.

BONAMINO, Alicia C. de. Avaliação educacional no Brasil 25 anos depois: onde estamos? In: BAUER, Adriana; GATTI, Bernardete A. (Org.). Vinte e cinco anos de avaliação de sistemas educacionais no Brasil: implicações nas redes de ensino, no currículo e na formação de professores. Florianópolis: Insular, 2013. p. $43-60$. 
BROOKE, Nigel P.; CUNHA, Maria A.; FALEIROS, Matheus. A avaliação externa como instrumento da gestão educacional nos estados: relatório final. Belo Horizonte: Game/UFMG; Fundação Victor Civita, 2011. Disponível em: $<$ http://www.fvc.org.br/pdf/relatorio-avaliacoes-externas.pdf > . Acesso em: 27 dez. 2012.

CARVALHO, Gisele F. da S. Avaliação oficial: subsídios para a compreensão do impacto na prática docente. 2010. Dissertação (Mestrado em Educação) - Universidade Federal de São João Del-Rei, São João Del-Rei, 2010.

CÔCO, Dilza. Avaliação externa da alfabetização: o Paebes - Alfa no Espírito Santo. 2014. Tese (Doutorado em Educação) - Universidade Federal do Espírito Santo, Vitória, 2014.

DUARTE, Adriane B. A participação das escolas públicas de educação básica no Saeb: implicações nas formas de organização e desenvolvimento do trabalho escolar. 2014. Dissertação (Mestrado em Educação) - Universidade Federal de Santa Maria, Santa Maria, RS, 2014.

FERRAROTTO, Luana. Promase: análise de uma experiência de avaliação do sistema municipal de ensino de Amparo. 2011. Dissertação (Mestrado em Educação) - Universidade Estadual de Campinas, Campinas, 2011.

FIGUEIREDO, Dione M. L. Gestão municipal, qualidade de ensino e a avaliação do rendimento escolar em um município de São Paulo. 2008. Tese (Doutorado em Educação) - Universidade Estadual Paulista "Júlio de Mesquita Filho", Araraquara, SP, 2008.

GEWEHR, Glaer Gianne. Avaliação da educação básica: políticas e práticas no contexto de escolas públicas municipais. 2010. Dissertação (Mestrado em Educação) - Pontifícia Universidade Católica do Paraná, Curitiba, 2010.

GIMENES, Nelson S.; SILVA, Vandré G.; PRÍNCIPE, Lizandra; LOUZANO, Paula; MORICONI, Gabriela. Além da Prova Brasil: investimento em sistemas próprios de avaliação externa. Estudos em Avaliação Educacional, São Paulo, v. 24, n. 55, p. 12-32, abr./ago. 2013.

GOMES, Carmem E. S. de L. Determinantes do baixo desempenho das escolas públicas municipais de Campos dos Goytacazes. 2009. Dissertação (Mestrado em Planejamento Regional e Gestão de Cidades) - Universidade Cândido Mendes, Campos dos Goytacazes, 2009.

GRAÇA, Heleonora C. da. No espelho da avaliação externa: o ensino público municipal de Aracaju. Estudos em Avaliação Educacional, São Paulo, v. 21, n. 47, p. 489-504, set./dez. 2010.

HORTA NETO, João L. Avaliação externa: a utilização dos resultados do Saeb 2003 na gestão do sistema público de ensino fundamental do Distrito Federal. 2006. Dissertação (Mestrado em Educação) - Universidade de Brasília, Brasília, 2006.

LIMA, Erisevelton S. 0 diretor e as avaliações aplicadas na escola. 2011. Tese (Doutorado em Educação) - Universidade de Brasília, Brasília, 2011. 
As avaliações externas e seus efeitos sobre as políticas educacionais: uma análise comparada entre a União e os estados de Minas Gerais e São Paulo. 2013. Tese (Doutorado em Política Social) - Instituto de Ciências Humanas, Universidade de Brasília, Brasília, 2013.

MARDEGAN, Eliene G. V. Avaliações externas e qualidade da educação: repercussões das avaliações em larga escala nos discursos sobre as práticas em escolas da rede municipal de São Paulo. 2014. Dissertação (Mestrado em Educação) - Universidade Cidade de São Paulo, São Paulo, 2014.

MARINHO, Railma A. C. Políticas públicas de avaliação: a avaliação externa e a realidade educacional da microrregião de Januária-MG. 2010. Dissertação (Mestrado em Educação) - Pontifícia Universidade Católica de Campinas, Campinas, 2010.

NASCIMENTO, Gilsimara P. do. Saeb: impactos de seus resultados e implicações nas políticas públicas educacionais no município de Jaboticatubas/MG. 2010. Dissertação (Mestrado em Educação) - Pontifícia Universidade Católica de Minas Gerais, Belo Horizonte, 2010.

OVANDO, Nataly G. A avaliação na política educacional de municípios sul-matogrossenses. 2011. Dissertação (Mestrado em Educação) - Faculdade de Educação, Universidade Federal da Grande Dourados, Dourados, MS, 2011.

PIMENTA, Cláudia O. As avaliações externas e o trabalho de coordenadores pedagógicos: estudo em uma rede municipal paulista. $2014.141 \mathrm{f}$. Dissertação (Mestrado) - Curso de Educação, Faculdade de Educação da Universidade de São Paulo, São Paulo, 2012.

PRUST, Kátia A. de C. Avaliação em larga escala no Paraná: um estudo sobre as provas e a repercussão no espaço escolar. 1999. Dissertação (Mestrado) Universidade Estadual de Londrina, Londrina, 1999.

RAHAL, Soraya. Políticas públicas de educação: o Saresp no cotidiano escolar. 2010. Dissertação (Mestrado) - Universidade Cidade de São Paulo, São Paulo, 2010.

ROCHA, Silvaneide de S. M. A inserção do Índice de Desenvolvimento da Educação Básica em escolas de ensino fundamental de Teresina-PI: um estímulo para a melhoria da educação? 2013. Dissertação (Mestrado) - Faculdade de Educação, Universidade de Brasília, Brasília, 2013.

SILVA, Maria J. de A. O sistema mineiro de avaliação da educação pública: impactos na escola fundamental de Uberlândia. 2005. Dissertação (Mestrado em Educação) - Universidade Federal de Minas Gerais, Belo Horizonte, 2005.

SOUSA, Sandra Z. Avaliação externa e em larga escala no âmbito do Estado brasileiro: interface de experiências estaduais e municipais de avaliação da educação básica com iniciativas do governo federal. In: BAUER, Adriana; GATTI, Bernardete A. (Org.). Vinte e cinco anos de avaliação de sistemas educacionais no Brasil: implicações nas redes de ensino, no currículo e na formação de professores. Florianópolis: Insular, 2013. p. 61- 85. 
SOUSA, Sandra Z.; PIMENTA, Cláudia O.; MACHADO, Cristiane. Avaliação e gestão municipal da educação. Estudos em Avaliação Educacional, São Paulo, v. 23, n. 53, p. 14-36, set./dez. 2012.

SOUZA, Elisete R. de. Accountability de professores: um estudo sobre o efeito da Prova Brasil em escolas de Brasília. 2009. Dissertação (Mestrado em Educação) - Faculdade de Educação, Universidade Estadual de Campinas, Campinas, 2009.

WERLE, Flávia O. C.; THUM, Adriane B.; ANDRADE, Alenis C. de. Processo nacional de avaliação do rendimento escolar: tema esquecido entre os Sistemas Municipais de Ensino. Ensaio: Avaliação e Políticas Públicas em Educação, Rio de Janeiro, v. 17, n. 64, p. 397-420, jul./set. 2009.

\section{ADRIANA BAUER}

Pesquisadora da Fundação Carlos Chagas (FCC). Professora doutora da Faculdade de Educação da Universidade de São Paulo (FE/USP), São Paulo, São Paulo, Brasil adbauer@fcc.org.br

\section{CLAUDIA OLIVEIRA PIMENTA}

Doutoranda em Educação da Faculdade de Educação da Universidade de São Paulo (FE/USP), São Paulo, São Paulo, Brasil t_cpimenta@fcc.org.br

\section{JOÃO LUIZ HORTA NETO}

Doutor em Educação pela Universidade de Brasília (UnB). Pesquisador do Instituto Nacional de Estudos e Pesquisas Educacionais Anísio Teixeira (Inep), Brasília, Distrito Federal, Brasil

jlhorta@gmail.com

\section{SANDRA ZÁKIA LIAN SOUSA}

Professora doutora da Faculdade de Educação da Universidade de São Paulo (FE/USP), São Paulo, São Paulo, Brasil sanzakia@usp.br 
